\title{
Prevalence of Dental Caries in Kosovar Adult Population
}

\author{
Blerim Kamberi, ${ }^{1}$ Ferit Koçani, ${ }^{1}$ Agim Begzati, ${ }^{2}$ Jeta Kelmendi, ${ }^{3}$ Donika Ilijazi, ${ }^{4}$ \\ Nora Berisha, ${ }^{3}$ and Lumnije Kqiku ${ }^{5}$ \\ ${ }^{1}$ Department of Dental Pathology and Endodontics, University Dentistry Clinical Center of Kosovo, 10000 Prishtina, Kosovo \\ ${ }^{2}$ Department of Pediatric and Preventive Dentistry, University Dentistry Clinical Center of Kosovo, 10000 Prishtina, Kosovo \\ ${ }^{3}$ Department of Orthodontics, University Dentistry Clinical Center of Kosovo, 10000 Prishtina, Kosovo \\ ${ }^{4}$ Private Dental Clinic, 10000 Prishtina, Kosovo \\ ${ }^{5}$ Division of Preventive and Operative Dentistry, Endodontics, Pedodontics and Minimally Invasive Dentistry, \\ Department of Dentistry and Maxillofacial Surgery, University of Graz, 8010 Graz, Austria
}

Correspondence should be addressed to Blerim Kamberi; blerimkamberi63@hotmail.com

Received 8 March 2016; Revised 18 May 2016; Accepted 26 June 2016

Academic Editor: Manal Awad

Copyright (C) 2016 Blerim Kamberi et al. This is an open access article distributed under the Creative Commons Attribution License, which permits unrestricted use, distribution, and reproduction in any medium, provided the original work is properly cited.

Objectives. The aim of this study was to assess the prevalence of dental caries in the Kosovar adult population. Materials and Methods. A cross-sectional study in Kosovo was conducted examining 9387 patients, aged 18 upwards, between January 2010 and December 2011. Clinical evaluation was done using WHO criteria for evaluation of dental health status and data collection. Results. The prevalence of caries for the whole study was $72.80 \%$. The mean DMFT index was $9.61( \pm 5.12)$ in the 18-34-year age group, $11.6( \pm 6.42)$ in the 35-44-year age group, $13.68( \pm 8.12)$ among the 45-64-year age group, $17.98( \pm 9.81)$ in the 65-74-year age group, and $23.19( \pm 9.41)$ in the age group of $75+$ years, respectively. A significant difference of mean DMFT and its each component was observed between the ages $(P<0.001)$. Conclusion. This study comes out with the significant levels of dental caries among young Kosovar population (18-34 years old).

\section{Introduction}

Dental caries continues to be a major health concern for populations worldwide. Damage caused by caries leads to a decrease in the quality of life of the affected individuals and high economic costs for both individuals and society, with disparities related to well-known issues of socioeconomics, immigration, lack of preventive efforts, and dietary changes [1]. Despite the overall decline in caries prevalence in developed countries [2], caries continues to be an important disease in most developing countries. Studies have shown that caries remains a major problem in the adult population of both developing and industrialized countries [3-5].

Evaluation of the oral health status in the adult age group is important because it presents important information for planning services in dental care and also generates data on the outcomes of dental care provided to the population during their lifetime [6].
In Kosovo, no studies have been conducted which include examination by dentists to determine the prevalence of caries or tooth loss among adults. Most epidemiological studies have focused mainly on children rather than adults [7]. Therefore, strategies that are needed to treat affected people remain unknown. Data collected in this study may be useful to build a more complete profile of the oral health status of the adult population of Kosovo and will supplement the analysis of global trends of the disease.

Therefore, the objective of this study was to assess the prevalence and severity of dental caries in the Kosovar adult population in relation to their sex, age, and place of residence (urban or rural).

\section{Materials and Methods}

2.1. Subjects. This was a cross-sectional study comprising 9387 patients from different regions of Kosovo aged 18-75+. 
They were examined between January 2010 and December 2011 at the University Dentistry Clinical Center of Kosovo.

The University Dentistry Clinical Center of Kosovo is the only secondary and tertiary care center for the whole territory of Kosovo. Within each year, a large number of populations use the free services at the center, hence providing a heterogeneous population sample. It was due to the latter fact that the authors decided to use population samples from this center's dental records for this study.

2.2. Data Collection. Data were collected based on age, sex, and residence (rural or urban). The exclusion criteria were patients under the age of 18 and those who were missing any of the required information.

For calibration, six examiners were trained by an experienced dentist prior to the clinical examinations. The interexaminer agreement determined by Cohen's Kappa values was 0.7-0.9.

In the WHO criteria used for clinical evaluation of health status and data collection, only the evaluation of hard tissue of the teeth was included [8]. Patients were examined under an artificial light, using a dental mirror and a dental probe. All present teeth were taken into consideration during the clinical examination. Diagnosis of dental caries was made according to the criteria recommended by the WHO [8] (i.e., when a lesion in a pit or fissure or on a smooth tooth surface had an unmistakable cavity, undermined enamel, or a detectably softened floor or wall). Caries severity was measured by DMFT index, which records the number of DT (decayed teeth), MT (missing teeth), and FT (filled teeth).

2.3. Data Analysis. Clinical data were first entered into modified WHO Oral Health Status [8] paper forms, then entered into Excel, and subsequently exported to Statistical Package for Social Sciences (SPSS 17.0 for Windows, 13.0 Program Package) for statistical analysis. The prevalence proportion rates, mean values, and standard deviations were calculated for the purpose of analysis. Statistical analysis was performed applying descriptive statistics and the independent sample Chi-square test, Fisher Exact test between different groups, and one-way ANOVA tests to compare the means of DMFT, DT, MT, and FT to the other variables. The level of statistical significance was set at $P=0.05$.

\section{Results}

Figure 1 shows characteristics of the subjects by sex and group. The number of female participants was 5337 (59.5\%), while the number of males was 4050 (40.5\%). Table 1 shows the subjects according to sex and residence. A total of $70.9 \%$ of subjects lived in the city while $29.1 \%$ lived in the countryside. According to sex, $73.3 \%$ of females and $67.6 \%$ of males lived in the city.

The highest percentage of participants diagnosed with caries was aged $18-34$ years (4152 participants, $44.2 \%$ ), while the lowest percentage was for participants aged 75 years and above $(2.9 \%)$. The other age groups had similar participation rates: $18.3 \%$ for patients aged $35-44$ years, $17.2 \%$ for patients aged $45-64$ years, and $17.3 \%$ for patients aged $65-74$ years.

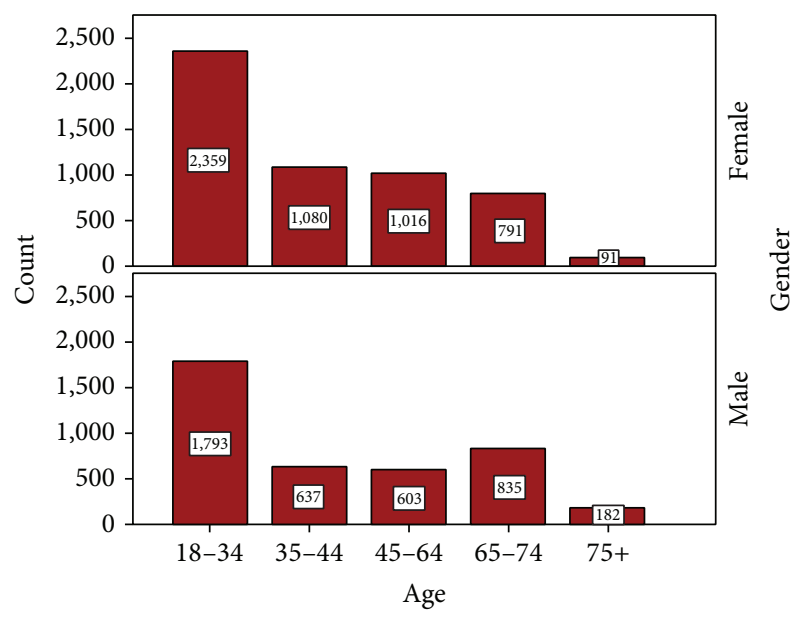

Figure 1: Patients participation according to sex and age group.

Our data show significant differences between sex and residence and between sex and age $(P<0.001)$. Table 2 shows the presence of caries according to sex, age, and residence.

According to the sex and caries distribution, 3903 patients (57.1\%) with caries were female, while 2929 (42.9\%) patients with caries were male.

Patients diagnosed with caries, $69.6 \%$, lived in the city, compared with $30.4 \%$ who lived in the countryside. The age group with the highest prevalence of caries was the 18-34year age group (54\%), and the age group with the lowest prevalence was the age group of $75+$ years $(0.8 \%)$. Using the Chi-square test, we compared caries prevalence according to sex and found no significant difference for $P=0.354$. However, when we compared caries prevalence according to age with caries prevalence according to residence, there was a significant difference in both comparisons for $P<0.001$.

Table 3 shows the DMFT and caries prevalence according to age and sex. The prevalence of caries for the whole study was $72.80 \%$, and it decreased with age: $18-34$ years $(88.80 \%)$, $34-44$ years $(77.90 \%), 45-64$ years $(65.50 \%), 65-74$ years $(42.40 \%)$, and $75+$ years $(20.90 \%)$. There was no significant difference between males and females.

The mean DMFT (SD) value for the study group was 12.52 $( \pm 7.91)$. The DMFT value increased with age from $9.61( \pm 5.12)$ for $18-34$ years to $11.6( \pm 6.42)$ for $35-44$ years, to $13.68( \pm 8.12)$ for $45-64$ years, to 17.98 ( \pm 9.87 ) for $65-74$ years, and to 23.19 $( \pm 9.41)$ for $75+$ years.

The analysis of the DMFT components showed that the MT score was the major component.

These variables were also tested with ANOVA, and, as shown in the table for the DMFT index, there is no significant difference between the means according to sex $(P=0.613)$. There was also no significant difference between the means according to sex for the DT and MT components, but there was a significant difference between the mean values according to sex for the FT component $(P<0.001)$.

Our results show significant differences between the means according to age in the DMFT index and all of its components with $P<0.001$. 
TABLE 1: Patients participation according to sex and residence.

\begin{tabular}{|c|c|c|c|c|c|c|c|}
\hline \multirow{2}{*}{ Sex } & \multicolumn{2}{|c|}{$\mathrm{F}$} & \multicolumn{2}{|c|}{$\mathrm{M}$} & \multicolumn{2}{|c|}{ Total } & \multirow{2}{*}{$P$ value } \\
\hline & $N$ & $\%$ & $N$ & $\%$ & $N$ & $\%$ & \\
\hline \multicolumn{8}{|l|}{ Residence } \\
\hline Rural & 1425 & 26.7 & 1311 & 32.4 & 2736 & 29.1 & \multirow{2}{*}{$P<0.001$} \\
\hline Urban & 3912 & 73.3 & 2739 & 67.6 & 6651 & 70.9 & \\
\hline
\end{tabular}

TABLE 2: Caries presence according to gender, age, and residence.

\begin{tabular}{|c|c|c|c|c|c|c|c|}
\hline \multirow{2}{*}{ Caries } & \multicolumn{2}{|c|}{ No } & \multicolumn{2}{|c|}{ Yes } & \multicolumn{2}{|c|}{ Total } & \multirow{2}{*}{$P$ value } \\
\hline & $N$ & $\%$ & $N$ & $\%$ & $N$ & $\%$ & \\
\hline \multicolumn{8}{|l|}{ Gender } \\
\hline Female & 1434 & 56.1 & 3903 & 57.1 & 5337 & 56.9 & \multirow{2}{*}{$P=0.354$} \\
\hline Male & 1123 & 43.9 & 2927 & 42.9 & 4050 & 43.1 & \\
\hline \multicolumn{8}{|l|}{ Age group } \\
\hline $18-34$ & 467 & 18.3 & 3685 & 54 & 4152 & 44.2 & \multirow{5}{*}{$P<0.001$} \\
\hline $35-44$ & 380 & 14.9 & 1337 & 19.6 & 1717 & 18.3 & \\
\hline $45-64$ & 558 & 21.8 & 1061 & 15.5 & 1619 & 17.2 & \\
\hline $65-74$ & 936 & 36.6 & 690 & 10.1 & 1626 & 17.3 & \\
\hline $75+$ & 216 & 8.4 & 57 & 0.8 & 273 & 2.9 & \\
\hline \multicolumn{8}{|l|}{ Residence } \\
\hline Rural & 659 & 25.8 & 2077 & 30.4 & 2736 & 29.1 & \multirow{2}{*}{$P<0.001$} \\
\hline Urban & 1898 & 74.2 & 4753 & 69.6 & 6651 & 70.9 & \\
\hline
\end{tabular}

TABLE 3: DMFT, D, M, and F and caries prevalence according to sex and age group.

\begin{tabular}{|c|c|c|c|c|c|c|c|c|c|}
\hline & \multicolumn{2}{|c|}{ DMFT } & \multicolumn{2}{|c|}{$\mathrm{D}$} & \multicolumn{2}{|c|}{ M } & \multicolumn{2}{|c|}{$\mathrm{F}$} & \multirow{2}{*}{ Caries prevalence } \\
\hline & Mean & $\mathrm{SD}$ & Mean & $\mathrm{SD}$ & Mean & SD & Mean & $\mathrm{SD}$ & \\
\hline \multicolumn{10}{|l|}{ Sex } \\
\hline Female & 12.56 & 7.682 & 3.25 & 3.339 & 7.1 & 8.538 & 2.21 & 2.962 & $73.10 \%$ \\
\hline Male & 12.47 & 8.206 & 3.03 & 3.268 & 7.6 & 9.214 & 1.84 & 2.725 & $72.30 \%$ \\
\hline \multirow[t]{2}{*}{ Total } & 12.52 & 7.912 & 3.15 & 3.31 & 7.31 & 8.839 & 2.05 & 2.868 & $72.80 \%$ \\
\hline & & $P=0.613$ & & $P=0.002$ & & $P=0.007$ & & $P<0.001$ & \\
\hline \multicolumn{10}{|l|}{ Age group } \\
\hline $18-34$ & 9.61 & 5.123 & 4.48 & 3.528 & 2.47 & 3.161 & 2.66 & 3.129 & $88.80 \%$ \\
\hline $35-44$ & 11.6 & 6.425 & 3.18 & 3.087 & 5.95 & 5.878 & 2.47 & 3.067 & $77.90 \%$ \\
\hline $45-64$ & 13.68 & 8.125 & 2.2 & 2.607 & 9.85 & 8.546 & 1.63 & 2.479 & $65.50 \%$ \\
\hline $65-74$ & 17.98 & 9.876 & 1.14 & 1.923 & 16.06 & 10.8 & 0.77 & 1.688 & $42.40 \%$ \\
\hline $75+$ & 23.19 & 9.419 & 0.53 & 1.453 & 22.35 & 10.095 & 0.32 & 0.972 & $20.90 \%$ \\
\hline \multirow[t]{2}{*}{ Total } & 12.52 & 7.912 & 3.15 & 3.31 & 7.31 & 8.839 & 2.05 & 2.868 & $72.80 \%$ \\
\hline & & $P<0.001$ & & $P<0.001$ & & $P<0.001$ & & $P<0.001$ & \\
\hline
\end{tabular}

Table 4 shows that caries prevalence was slightly higher for patients living in rural areas $(75.9 \%)$ than for patients living in urban areas (71.5\%).

The highest mean value and SD were for the MT component with a value of $7.31 \pm 8.83$, followed by the DT component with a mean value of $3.15 \pm 3.31$, and the FT component with the lowest mean value of $2.05 \pm 2.86$.

Comparing the mean values of the DMFT index and its components according to the patients' residence, we found no significant difference for the MT component with $P=0.617$.
Patients from an urban residence had a higher DMFT index compared with those from a rural residence with a significant difference for $P<0.05$.

Comparing the averages of the DT and FT components according to residence using one-way ANOVA test, we found that the average DT component was higher among the rural population $(3.44 \pm 3.45)$ than among the urban population $(3.03 \pm 3.24)$ with no significant difference for $P<0.001$, although the average FT component was higher among the urban population $(3.01 \pm 2.26)$ than among the rural 
TABLE 4: DMFT, D, M, and F and caries prevalence according to residence.

\begin{tabular}{lccccccccc}
\hline & \multicolumn{2}{c}{ DMFT } & \multicolumn{2}{c}{ D } & M & & F & Caries prevalence \\
& Mean & SD & Mean & SD & Mean & SD & Mean & SD \\
\hline Residence & & & & & & & & \\
Rural & 12.23 & 7.862 & 3.44 & 3.459 & 7.24 & 8.631 & 1.54 & 2.411 & $75.90 \%$ \\
Urban & 12.64 & 7.93 & 3.03 & 3.24 & 7.34 & 8.924 & 2.26 & 3.011 & $71.50 \%$ \\
\hline Total & 12.52 & 7.912 & 3.15 & 3.31 & 7.31 & 8.839 & 2.05 & 2.868 \\
\hline
\end{tabular}

population $(1.54 \pm 2.41)$ with a highly significant difference for $P<0.001$.

\section{Discussion}

Most studies about dental caries in Kosovo have focused on children under 12 years of age, and the state of dental caries in adults has remained unknown. A previous study assessing the prevalence and analyzing caries risk factors, in the Kosovar population between 2002 and 2005, had included measurements of early childhood caries, DEFT, and DMFT [7]. This is the first study that has investigated the epidemiology of dental caries among adults in Kosovo.

In agreement with most studies [9-11], it was found that the prevalence of caries was slightly higher in females than in males (Table 2). However, the present study did not observe any significant sex differences in caries prevalence that was confirmed in earlier findings $[12,13]$.

According to WHO recommendations, oral health surveillance of oral health conditions in adults should include the 35-44-year age group and the 65-74-year age group [8]. In our study, in addition to these two age groups, we included the age groups of 18-34 years, 45-64 years, and over 75 years (Figure 1). The prevalence of dental caries in the 18-34-year age group in the present study was found to be the highest. This outcome is thought to be a result of poor socioeconomic development, lack of preventive services in health insurance, and inadequate knowledge about the importance of oral health as a consequence of the absence of oral health promotion programs in adults.

The caries prevalence for the 35-44-year age group has been reported in many studies [14-16]. In the present study, the prevalence of dental caries in this age group was found to be $77.90 \%$, which is lower than in some previous studies $[14,15,17]$ but higher than in the studies conducted by Doifode et al. (48.6\%) [16] and Namal et al. (58.2\%) [5]. Our results showed that as age increased, the prevalence of caries decreased, which is in contrast with other research findings showing that as age increases so does the prevalence of caries [18]. This holds true since with age the prevalence of missing teeth increases compared to the prevalence of decayed and filled teeth.

Differences in the prevalence rates may be due to different study criteria. Observed differences in the caries prevalence of the adult population suggest that it may be possible to develop and implement oral health policies taking into account geographical and socioeconomic differences in populations [19].
Differences in the prevalence of caries between urban and rural areas are narrowing as the socioeconomic development in rural areas increases. Therefore, the prevalence of caries in some rural areas was even higher than in urban areas [20], which could be a result of lower level of oral health education and socioeconomic status. However, our study shows no significant difference in caries prevalence between urban and rural subjects (Table 4), which is in accordance with a study in the United States [21].

The mean DMFT for the study sample was 12.52 and increased among the ages (Table 3 ) and is consistent with the results of other studies [22, 23].

By the latest data, the mean DMFT value observed among 18-34-year age group was 9.61, compared to a value of 4.37 in an 18-25-year age group [24] in a neighbouring region, Italy, and 12.76 in a 20-34-year age group [19] in Hungary; our score shows moderate condition among this population, which means a relative "average position" for Kosovo.

In the 35-44-year age group, the mean DMFT value was 11.6, which was a better score than in many countries; DMFT scores for the same age group were 16.1 in Germany [25], 15.4 in Belgium [26], 14.7 in Austria [27], 15.4 in Hungary [19], and 14.4 in Norway [28]. However, the mean DMFT score in our study for individuals aged $65-74$ years (17.98) was higher than in many other countries $[19,25,27]$.

Comparisons of the mean DMFT findings with those of other studies should be undertaken with caution, since there is great variation in the findings in the literature. This discrepancy may be due to differences in geographic location, population culture, diagnostic criteria, and sampling procedures.

The value of F/DMFT observed in our study was 2.47 for the 35-44-year age group and only 0.77 for the 65-74year age group. These values are significantly lower than those in certain European countries such as Spain, Denmark, Austria, and France, where patients have a higher proportion of fillings than in Kosovo [17, 27, 29, 30]. A potential reason for this might be that people in Kosovo tend to seek dental care when they experience severe dental pain rather than for routine dental checkups; hence, by the time they seek dental care, the caries is at an advanced stage. In most cases, the tooth has to be extracted because it is beyond restoration or requires complex and expensive endodontic treatment. The high percentage of untreated teeth in individuals aged 65-74 years may be due to difficulties in accessing dental services and a lack of interest in dental health or due to other health conditions. 
It was also noted that the DT component decreased with age while the MT component increased with age. Reasons for the high prevalence of decayed teeth in adults aged 18-34 years, together with the low prevalence of filled teeth in comparison with other European countries, are mainly a consequence of the health insurance system in Kosovo.

Fillings and endodontic treatment are free for about $40 \%$ of the Kosovar population covered by the private health insurance system, which still does not include free preventive measures and guidelines for adults. In summary, the high prevalence of decayed, missing, and filled teeth in the adult population of Kosovo also reflects the lack of preventive services in the state health insurance system.

There is a high DT component and there is a very low FT component of the DMFT, mainly because of the lack of restorative dental services or to some extent low utilization of this service.

As a consequence of the absence of the data, we were not able to compare our results with neighboring states.

\section{Conclusion}

The present study demonstrated significant levels of dental caries among young Kosovar population (18-34 years old) where carious and missing teeth due to caries are predominant.

It is understandable that Kosovo, as a new state with major economic and social problems and with a developing health care department, has a significant number of priorities to balance with the dental-oral health care of the population. Therefore, based on the WHO recommendations, to improve the general oral health of the population, the focus should be on prevention, starting with health education, promotion of oral health, and application of preventive measures in the Kosovar population.

Further studies of dental health that cover more regions of Kosovo will help to identify public dental health problems, an essential step in improving the general health status of the citizens of this country [31].

\section{Ethical Approval}

The protocols and the human data that we used in this study were approved by the Ethical Board of the University Dentistry Clinical Center of Kosovo.

\section{Competing Interests}

The authors would like to declare that there are no competing interests related to this paper.

\section{Acknowledgments}

This study was supported by and obtained the data from the University Dentistry Clinical Center of Kosovo conducted by the Ministry of Health.

\section{References}

[1] R. A. Bagramian, F. Garcia-Godoy, and A. R. Volpe, "The global increase in dental caries. A pending public health crisis," American Journal of Dentistry, vol. 22, no. 1, pp. 3-8, 2009.

[2] P. E. Petersen, “The World Oral Health Report 2003: continuous improvement of oral health in the 21st century-the approach of the WHO Global Oral Health Programme," Community Dentistry and Oral Epidemiology, vol. 31, no. 1, pp. 3-24, 2003.

[3] W.-M. Luan, V. Baelum, O. Fejerskov, and X. Chen, "Ten-year incidence of dental caries in adult and elderly Chinese," Caries Research, vol. 34, no. 3, pp. 205-213, 2000.

[4] E. Treasure, M. Kelly, N. Nuttall, J. Nunn, G. Bradnock, and D. White, "Factors associated with oral health: a multivariate analysis of results from the 1998 adult dental health survey," British Dental Journal, vol. 190, no. 2, pp. 60-68, 2001.

[5] N. Namal, G. Can, S. Vehid, S. Koksal, and A. Kaypmaz, "Dental health status and risk factors for dental caries in adults in Istanbul, Turkey," Eastern Mediterranean Health Journal, vol. 14, no. 1, pp. 110-118, 2008.

[6] O. Fejerskov and E. A. M. Kidd, Dental Caries: The Disease and Its Clinical Management, Blackwell Munksgaard, Oxford, UK, 2008.

[7] A. Begzati, K. Meqa, D. Siegenthaler, M. Berisha, and W. Mautsch, "Dental health evaluation of children in Kosovo," European Journal of Dentistry, vol. 5, no. 1, pp. 32-39, 2011.

[8] World Health Organization, Oral Health Surveys: Basic Methods, World Health Organization, Geneva, Switzerland, 1997.

[9] J. O. García-Cortés, C. E. Medina-Solís, J. P. Loyola-Rodriguez et al., "Dental caries' experience, prevalence and severity in Mexican adolescents and young adults," Revista de Salud Publica, vol. 11, no. 1, pp. 82-91, 2009.

[10] A. P. Pontigo-Loyola, C. E. Medina-Solis, S. A. Borges-Yañez, N. Patiño-Marín, A. Islas-Márquez, and G. Maupome, "Prevalence and severity of dental caries in adolescents aged 12 and 15 living in communities with various fluoride concentrations," Journal of Public Health Dentistry, vol. 67, no. 1, pp. 8-13, 2007.

[11] C. E. Medina-Solís, G. Maupomé, B. Pelcastre-Villafuerte, L. Avila-Burgos, A. A. Vallejos-Sánchez, and A. J. CasanovaRosado, "Socioeconomic inequalities in oral healt: dental caries in 6 to 12 year-old children," Revista de Investigacion Clinica, vol. 58, no. 4, pp. 296-304, 2006.

[12] N. Shah and K. R. Sundaram, "Impact of socio-demographic variables, oral hygiene practices, oral habits and diet on dental caries experience of Indian elderly: a community-based study," Gerodontology, vol. 21, no. 1, pp. 43-50, 2004.

[13] A. M. Maru and S. Narendran, "Epidemiology of dental caries among adults in a rural area in India," Journal of Contemporary Dental Practice, vol. 13, no. 3, pp. 382-388, 2012.

[14] E. Mamai-Homata, V. Topitsoglou, C. Oulis, V. Margaritis, and A. Polychronopoulou, "Risk indicators of coronal and root caries in Greek middle aged adults and senior citizens," BMC Public Health, vol. 12, no. 1, article 484, 2012.

[15] C. Splieth, C. Schwahn, O. Bernhardt et al., "Caries prevalence in an adult population: results of the Study of Health in Pomerania, Germany (SHIP)," Oral Health \& Preventive Dentistry, vol. 1, no. 2, pp. 149-155, 2003.

[16] V. V. Doifode, N. N. Ambadekar, and A. G. Lanewar, "Assessment of oral health status and its association with some epidemiological factors in population of Nagpur, India," Indian Journal of Medical Sciences, vol. 54, no. 7, pp. 261-269, 2000. 
[17] M.-V. Eustaquio, J.-M. Montiel, and J.-M. Almerich, "Oral health survey of the adult population of the Valencia region (Spain)," Medicina Oral, Patologia Oral, Cirugia Bucal, vol. 15, no. 3, pp. e538-e544, 2010.

[18] T. Loh, J. Chan, and C. N. Low, "Oral health of Singapore adults," Singapore Dental Journal, vol. 21, no. 1, pp. 6-10, 1996.

[19] M. Madléna, P. Hermann, M. Jáhn, and P. Fejérdy, "Caries prevalence and tooth loss in Hungarian adult population: results of a national survey," BMC Public Health, vol. 8, article 364, 2008.

[20] D. E. Diehnelt and H. A. Kiyak, "Socioeconomic factors that affect international caries levels," Community Dentistry and Oral Epidemiology, vol. 29, no. 3, pp. 226-233, 2001.

[21] C. M. Vargas, J. A. Yellowitz, and K. L. Hayes, "Oral health status of older rural adults in the United States," The Journal of the American Dental Association, vol. 134, no. 4, pp. 479-486, 2003.

[22] J.-M. Brodeur, M. Payette, M. Benigeri, P. F. Gagnon, M. Olivier, and D. Chabot, "Dental caries in Quebec adults aged 35 to 44 years," Journal of the Canadian Dental Association, vol. 66, no. 7, pp. 374-379, 2000.

[23] D. S. Brennan and A. J. Spencer, "Changes in caries experience among Australian public dental patients between 1995/96 and 2001/02," Australian and New Zealand Journal of Public Health, vol. 28, no. 6, pp. 542-548, 2004.

[24] M. Vano, S. Gennai, D. Karapetsa et al., "The influence of educational level and oral hygiene behaviours on DMFT index and CPITN index in an adult Italian population: an epidemiological study," International Journal of Dental Hygiene, vol. 13, no. 2, pp. 151-157, 2015.

[25] U. Schiffner and E. Reich, "Caries in adolescents, adults and seniors in Germany," Caries Research, vol. 33, p. 286, 1999.

[26] P. Bercy, J. Meurisse, M. Lambert, and R. Tonglet, "Application of the CPITN in a group of 35-65 Years-old Belgian employees. Comparison with different parameters," Journal Dental Research, vol. 77, article 831, 1998.

[27] P. Städtler, A. Bodenwinkler, and G. Sax, "Caries prevalence in a 35-44 and 65-74 year-old Austrian population," Caries Research, vol. 36, p. 2007, 2002.

[28] D. Holst, A. Schuller, and K. Dahl, "Tannhelseutviklingen i den voksne befolkningen i Nord-Trøndelag fra 1973 til 2006," Norske Tannlegeforenings Tidende, vol. 11, pp. 804-811, 2007.

[29] U. Krustrup and P. Petersen, "Oral health status of adults in Denmark," Community Dental Health, vol. 19, p. 202, 2002.

[30] P. Hescot, D. Bourgeois, and J. Doury, "Oral health in 35-44 year old adults in France," International Dental Journal, vol. 47, no. 2, pp. 94-99, 1997.

[31] B. Kamberi, V. Hoxha, M. Stavileci, E. Dragusha, A. Kuçi, and L. $\mathrm{Kqiku}$, "Prevalence of apical periodontitis and endodontic treatment in a Kosovar adult population," BMC Oral Health, vol. 11, no. 1, article 32, 2011. 


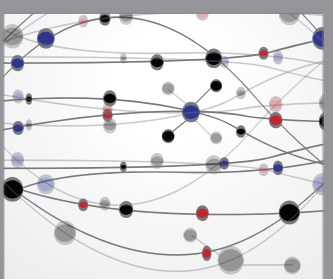

The Scientific World Journal
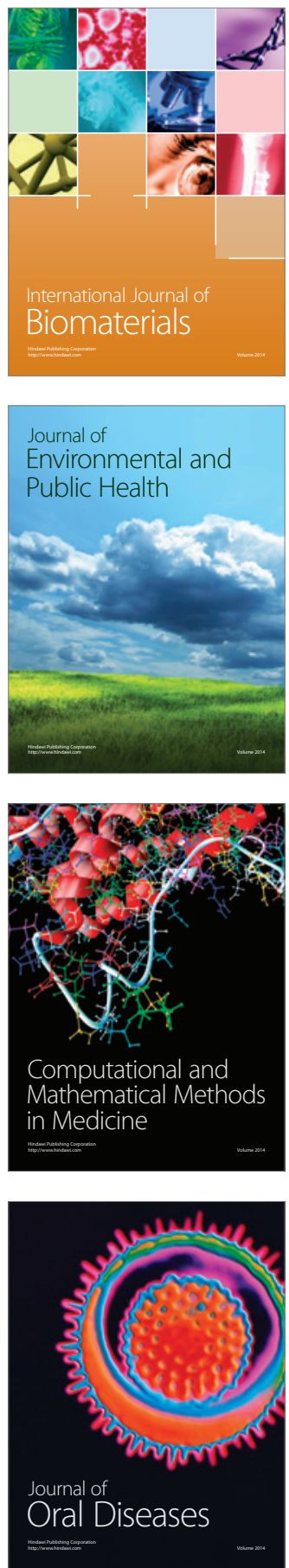
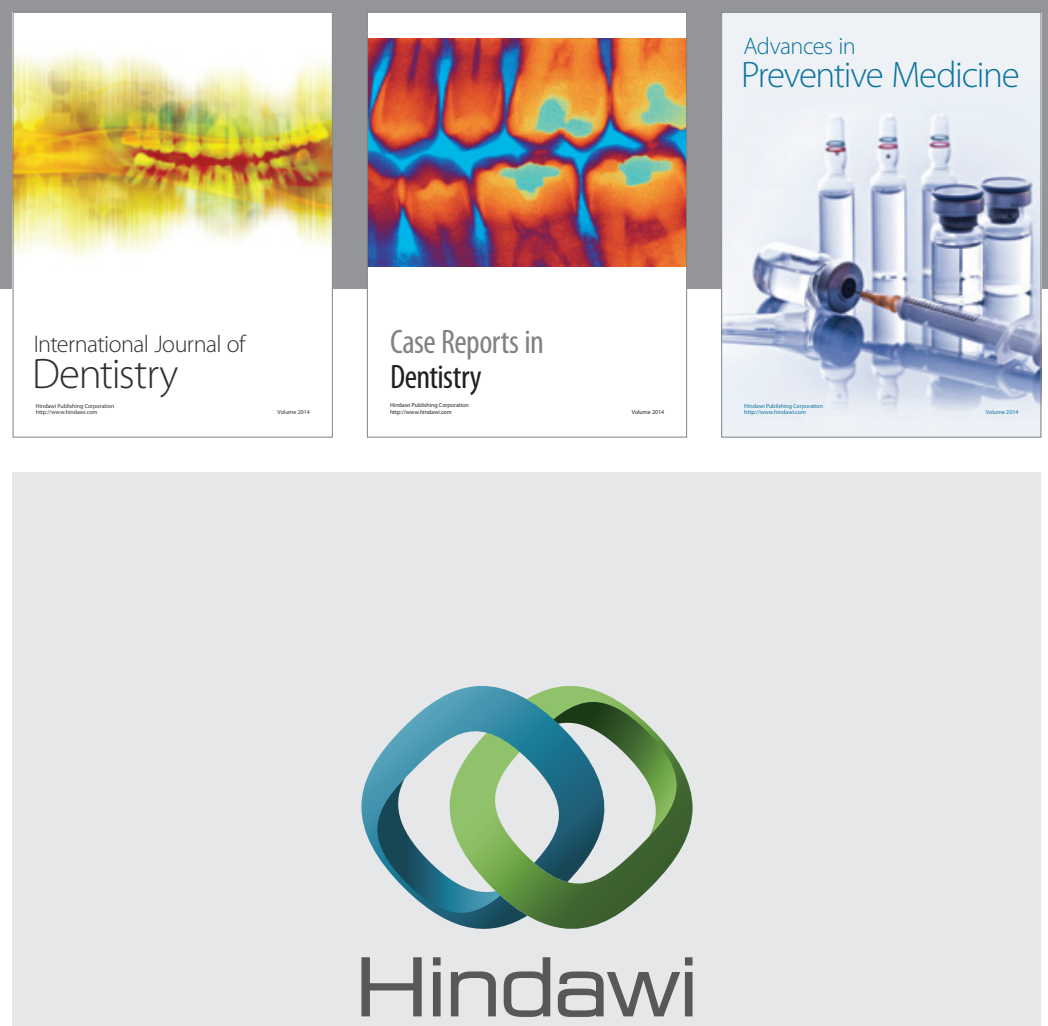

Submit your manuscripts at

http://www.hindawi.com
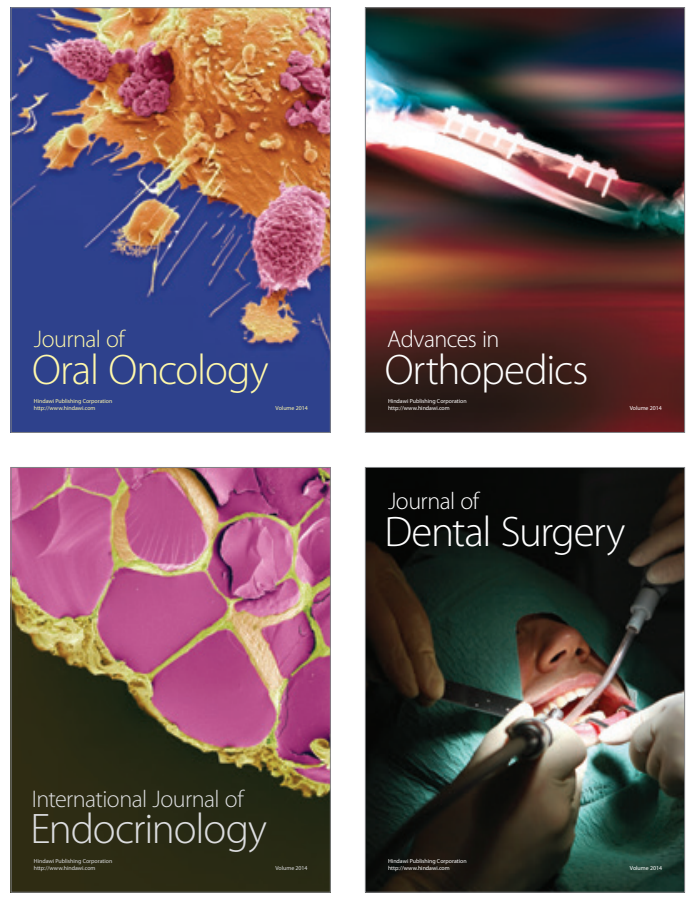
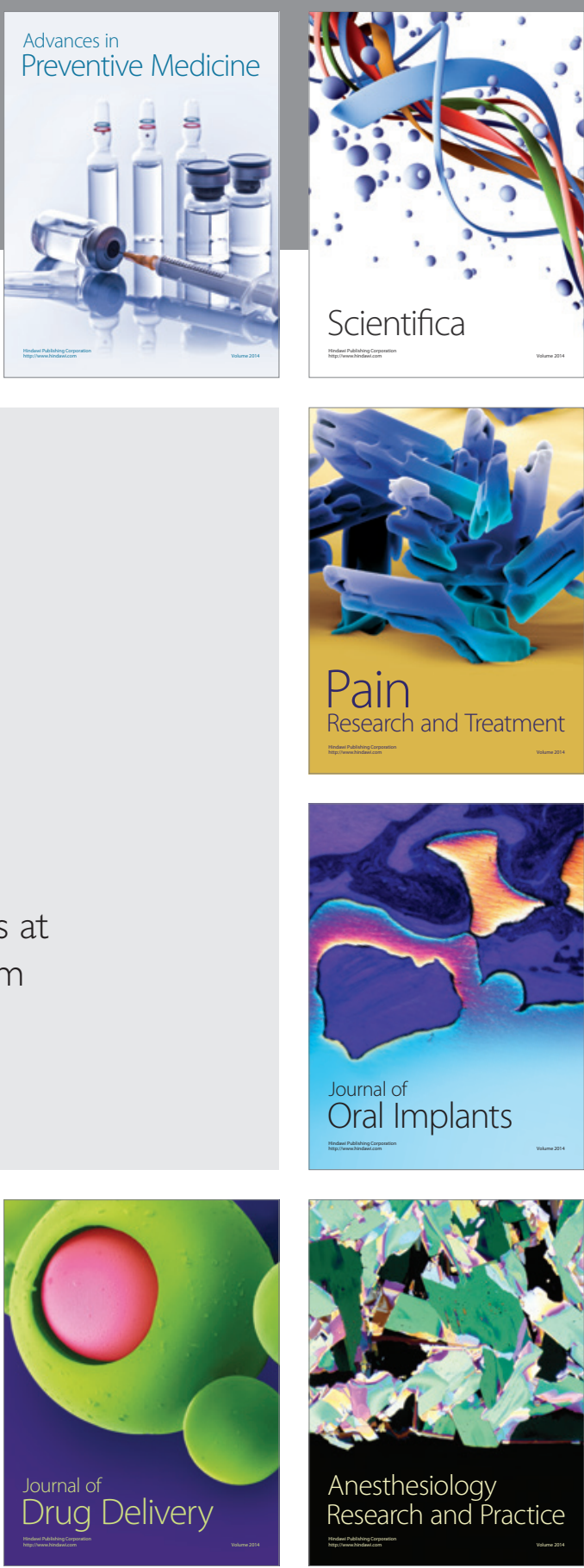

Scientifica
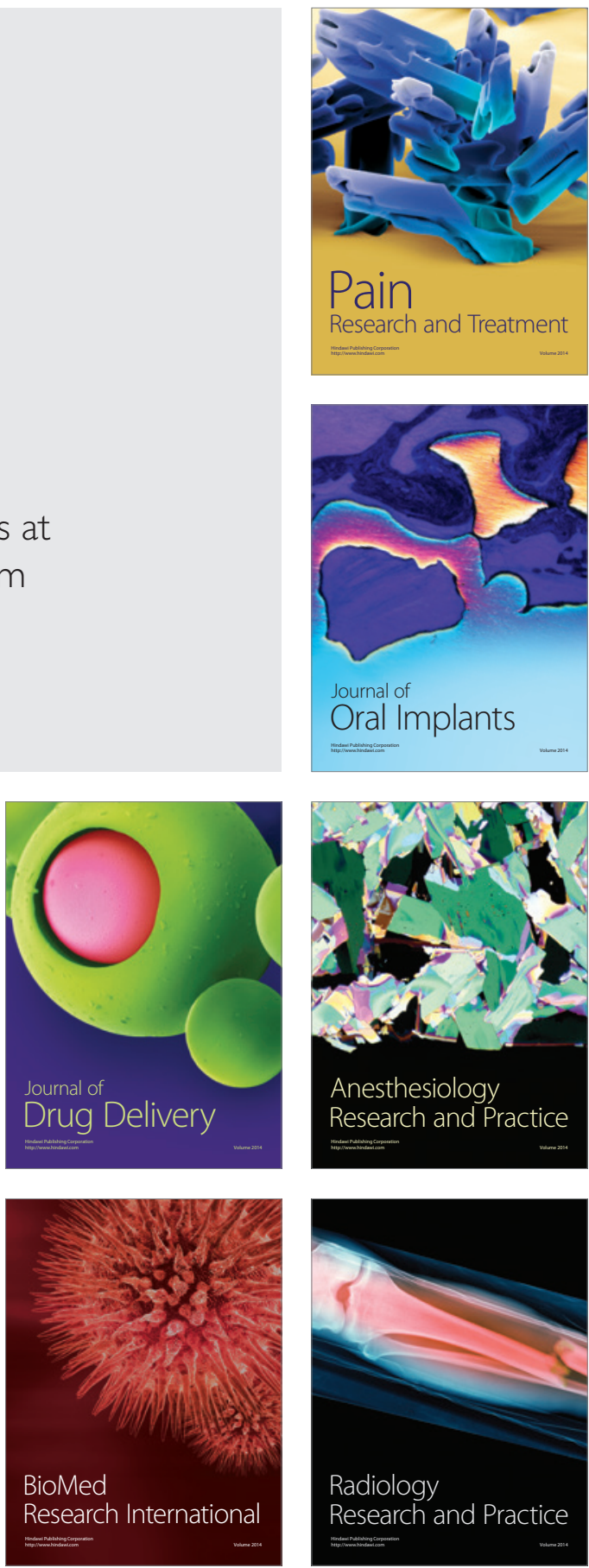